\title{
Inhibition of Growth of Highly Resistant Bacterial and Fungal Pathogens by a Natural Product
}

\author{
Rand R. Hafidh ${ }^{1,2}$, Ahmed S. Abdulamir ${ }^{2,3}$, Law Se Vern ${ }^{4}$, Fatimah Abu Bakar, ${ }^{4, *}$ Faridah Abas ${ }^{4}$, \\ Fatemeh Jahanshiri ${ }^{5}$ and Zamberi Sekawi ${ }^{6}$
}

\author{
${ }^{I}$ Department of Microbiology, College of Medicine, Baghdad University, Baghdad-Iraq \\ ${ }^{2}$ Institute of Bioscience, Universiti Putra Malaysia, 43400 UPM Serdang, Selangor Darul Ehsan \\ ${ }^{3}$ Department of Microbiology, College of Medicine, Al-Nahrain University, Baghdad-Iraq \\ ${ }^{4}$ Department of Food Science, Faculty of Food Science and Technology, Universiti Putra Malaysia, 43400 UPM \\ Serdang, Selangor Darul Ehsan \\ ${ }^{5}$ Department of Microbiology, Faculty of Biotechnology and Biomolecular Sciences, Univirsiti Putra Malaysia, 43400 \\ UPM Serdang, Selangor Darul Ehsan \\ ${ }^{6}$ Department of Medical Microbiology and Parasitology, Faculty of Medicine and Health Sciences, Universiti Putra \\ Malaysia, 43400 UPM Serdang, Selangor Darul Ehsan
}

\begin{abstract}
The continuous escalation of resistant bacteria against a wide range of antibiotics necessitates discovering novel unconventional sources of antibiotics. B. oleracea $\mathrm{L}$ (red cabbage) is health-promoting food with proven anticancer and anti-inflammatory activities. However, it has not been researched adequately for its antimicrobial activity on potential resistant pathogens. The methanol crude extract of B. oleracea L. was investigated for a possible anti-microbial activity. The screening method was conducted using disc diffusion assay against 22 pathogenic bacteria and fungi. It was followed by evaluation of the minimum inhibitory concentration (MIC). Moreover, the antibacterial and the antifungal activities were confirmed using the minimum bactericidal concentration (MBC) and the minimum fungicidal concentration (MFC), respectively. Remarkable, antibacterial activity was evident particularly against highly infectious microorganisms such as Methicillin-resistant Staphylococcus aureus, Escherichia coli O157:H7, Pseudomonas aeruginosa, Klebsiella pneumoniae, Staphylococcus aureus, and Salmonella enterica serovar Typhimurium as well as against human fungal pathogens, Trichophyton rubrum and Aspergillus terreus. Red cabbage is a rich source of phenolic compounds, anthocyanins being the most abundant class, which might explain its potent antimicrobial action. This extract is potentially novel for future antimicrobials, inexpensive, and readily available at a large scale for pharmaceutical companies for further investigation and processing.
\end{abstract}

Keywords: Antibacterial, antifungal, red cabbage, anthocyanins.

\section{INTRODUCTION}

As a result of the indiscriminate use of antimicrobial drugs in the treatment of infectious diseases, microorganisms have developed resistance to many antibiotics [1]. Recently, methicillin-resistant Staphylococcus aureus (MRSA), Escherichia coli O157:H7, Mycobacterium tuberculosis, and Pseudomonas aeruginosa are considered some of the most virulent microorganisms for the human population [2]. Therefore, there is a critical need to move fast and develop alternative antimicrobial drugs. One approach is to screen local medicinal plants which represent a rich source of novel antimicrobial agents. Medicinal plants are an integral component of research development in microbiology and

*Address correspondence to this author at the Food Science Department, Faculty of Food Science and Technology, Universiti Putra Malaysia, 43400 Serdang, Selangor, Malaysia; Tel: 00-60-(0)3-89468375; Fax: 00-60-(0)389423552; E-mail: fatimah_upm_fst@yahoo.com pharmaceutical industry. Natural products from plants have traditionally provided the pharmaceutical industry with one of its most important sources of lead compounds; up to $40 \%$ of modern drugs are derived from natural sources using either natural substances or synthesized versions [3].

Flavonoids have been shown to be associated with many of biological effects such as antibacterial, antiviral, antiinflammatory, antiplatelet, antioxidant, free radical scavenging, and vasodilatory actions [4]. High activity of flavonoids and antioxidant was found in intensely colored vegetables, such as red cabbage, red onion, etc. [5] rendering them as likely sources of novel antimicrobial activities that in the future might lead to a breakthrough discovery of new antibiotics or antifungal drugs. On the other hand, synthetic chemicals have long been used as active agents in reducing the incidence of diseases in plants, animals and humans; however, these drugs are not cheap and takes a lot of effort to produce [1]. Therefore, there is a need to search more on 
new resources such as medicinal plants. Medicinal plants have become very necessary to provide the society with cheap and even effective medical alternative drugs. Such medicinal plant products are believed to be highly crucial to improve the society health level and prevent the development of serious diseases [6].

Red cabbage (Brassica oleracea L. var. capitata f. rubra DC), which belongs to the family Brassicaceae is one of the most important vegetables grown worldwide [7]. Recently, red cabbage has attracted much attention because of its physiological functions and applications. There were some studies conducted on red cabbage extract proving its anticancer [8, 9], anti-inflammatory [10], anti-diabetic effects [11]. However, only two studies for its antibacterial effects were done worldwide $[12,13]$.

To the best of our knowledge, there was no previous study covered the antimicrobial effect of the red cabbage extract against E. coli O157:H7, MRSA, Staphylococcus aureus, Salmonella enterica serovar Typhimurium, Pseudomonas aeruginosa, and Klebsiella pneumoniae. This study was also carried out to explore, for the first time, the antifungal effect of red cabbage methanol crude extract against 10 different fungal species. This study is believed to be the cornerstone for further development with regards to red cabbage extract to specify exactly the antibacterial and antifungal compounds and their mechanism of action.

\section{MATERIALS AND METHODS}

\section{Plant Material and Preparation of the Extract}

Fresh red cabbage was purchased from local markets in the state of Selangor, Malaysia. The cabbage leaves were chopped into small pieces and left to dry at room temperature in dark area for approximately 7 days. After drying the leaves were ground to powder. The ground powder was extracted $1: 10, \mathrm{wt} / \mathrm{v}$ with $2.4 \mathrm{~mol} / \mathrm{L} \mathrm{HCl}$ acidified methanol (Merck, Darmstadt, Germany) to extract all phenolic compounds, free and conjugated [14] and soaked for three days in dark at room temperature. The solvent was then removed by filtration and fresh solvent was then added to the plant material. The extraction procedure was repeated twice and extracts were combined and evaporated to dryness under vacuum at $40^{\circ} \mathrm{C}$. The $\mathrm{pH}$ of red cabbage leaves extract ranged from 6.8 to 7.2 which is a neutral $\mathrm{pH}$. The powder was stored at $-18^{\circ} \mathrm{C}$.

\section{Microorganisms and Media}

A total of 22 microorganisms consisting of 12 bacteria and 10 fungi were used in this study (Table $\mathbf{1}$ and $\mathbf{3}$ ). All of the microorganisms were obtained from the microbiology laboratory of the Institute of Bioscience, University Putra Malaysia. Bacteria, other than ATCC strains, were identified by the use of biochemical profiles according to the recommendations of the manual of clinical microbiology [15] while fungi, other than ATCC strains, were identified depending on the macroand micro- scopic features [16]. The tested bacteria and fungi were maintained on nutrient agar (Merck, Darmstadt, Germany) and sabouraud dextrose agar slants (Merck, Darmstadt, Germany), respectively, at $4^{\circ} \mathrm{C}$ until further use.

The tested bacteria were subjected to a panel of antibiotic susceptibility discs (BBL, USA) for profiling their antibiotic sensitivity. Out of 12 tested bacteria, three multiple drug resistant (MDR) bacteria were found. The MDR bacteria were MRSA, $P$. aeruginosa, and Enterohemorrhagic (EHEC) E. coli O157:H7 which were highly resistant to more than four antibiotics. Isolates other than MDR and ATCC strains were either resistant to one antibiotic or not resistant to any of the tested antibiotics. MRSA isolate was completely resistant to oxacillin, erythromycin, streptomycin, clindamycin and tetracycline. Moreover, the MRSA isolate was a bit borderline resistant to vancomycin, namely vancomycin-intermediate Staphylococcus aureus (VISA). The MDR $P$. aeruginosa isolate was resistant to ceftazidime, ciprofloxacin, cefepime, imipenem, and piperacillin/ tazobactam. The MDR E. coli $\mathrm{O} 157: \mathrm{H} 7$ isolate was resistant to ampicillin, kanamycin, sulfisoxazole, and tetracycline. Therefore, nine non-MDR and three MDR bacteria were used to test the antibacterial effect of red cabbage leaves extract.

\section{ANTIMICROBIAL SENSITIVITY TESTS}

\section{Disc Diffusion Assay}

The dried plant extracts were dissolved in the same solvent, methanol, to final concentrations of 200 and $500 \mathrm{mg} / \mathrm{ml}$ for antibacterial tests and 200, 500 and $700 \mathrm{mg} / \mathrm{ml}$ for antifungal tests and were sterilized by filtration through $0.45 \mu \mathrm{m}$ Millipore filters (Nalgene, UK). The primary screening antimicrobial test was carried out by disc diffusion [15] using $100 \mu \mathrm{l}$ of suspension containing $10^{8} \mathrm{CFU} / \mathrm{ml}$ of bacteria and $10^{5} \mathrm{spore} / \mathrm{ml}$ of fungi, spread evenly on the surface of the nutrient agar and sabouraud dextrose agar plates, respectively. Sterile Whatman No. 1 filter paper (MACHEREYNAGEL, MN 615, Germany) was used to prepare $6 \mathrm{~mm}$ in diameter discs. These discs were processed, in triplicates, to contain $10 \mu \mathrm{l}$ of the extract, i.e.; $(2 \mathrm{mg} / \mathrm{disc}),(5 \mathrm{mg} / \mathrm{disc})$ and $(7 \mathrm{mg} /$ disc $)$ for extract concentrations $(200 \mathrm{mg} / \mathrm{ml}),(500$ $\mathrm{mg} / \mathrm{ml})$ and $(700 \mathrm{mg} / \mathrm{ml})$, respectively; these discs were then impregnated in the inoculated agar. Negative controls were prepared, in triplicates per Petri dish, using the same solvents employed to dissolve the plant extracts. Ten $\mu \mathrm{g} / \mathrm{disc}$ of Streptomycin (CALBIOCHEM, China) and Amphotericin B (Sigma, Steinheim, Germany) were used, in triplicates per Petri dish, as positive controls or reference standard drugs for comparing the sensitivity of tested bacteria and fungi, respectively, with the test extract. For bacteria, the inoculated plates were incubated for $24 \mathrm{~h}$ at $37^{\circ} \mathrm{C}$ and, for fungi, the inoculated plates were incubated for $3-5$ days at $30-35^{\circ} \mathrm{C}$. Clear inhibition zones around discs indicated the presence of antimicrobial activity. For optimal fidelity of results, each assay was repeated three times.

\section{Microdilution Assay}

The minimum inhibitory concentration (MIC) values were also studied for the microorganisms found sensitive to the extract by using disc diffusion assay. The MIC is defined as the lowest concentration of the compounds to inhibit the growth of microorganisms. The microdilution method was used according to the methodology referred by [17] with some modifications. The inocula of bacteria were prepared from $12 \mathrm{~h}$ broth cultures and standardized to $10^{8} \mathrm{CFU} / \mathrm{ml}$. And fungal inocula were prepared from 3-5 days fresh fungal cultures, depending on the fungus type, and standardized 
to $10^{5} \mathrm{spore} / \mathrm{ml}$. Stock extracts of 1200 and $700 \mathrm{mg} / \mathrm{ml} \mathrm{con-}$ centrations were prepared in 10\% dimethylsulfoxide (Merck, Darmstadt, Germany) for bacterial and fungal tests, respectively. Serial dilutions of the stock extract solutions were prepared in concentrations range from 0 to $600 \mathrm{mg} / \mathrm{ml}$ for bacteria and 0 to $350 \mathrm{mg} / \mathrm{ml}$ for fungi. For bacteria, the extract solution was diluted using nutrient broth (Merck, Darmstadt, Germany) and, for fungi, the extract solution was diluted in sabouraud dextrose broth (Merck, Darmstadt, Germany). One hundred microlitter of the stock extract was transferred to each of the first three wells of the first column to prepare the first extract dilution then $100 \mu \mathrm{l} /$ well of each microorganism suspension were dispensed into 96-well flat-bottom microtiter plate (Steriline, UK). From the first column, $100 \mu \mathrm{l}$ from each well was transferred to the wells of the next column to prepare the second extract dilution with $100 \mu \mathrm{l} /$ well of the microorganism. The rest of the extract dilutions were prepared by the same method. On the other hand, triplicates of extract-free bacterial and fungal spore suspensions were used as negative controls as well as triplicates of streptomycin at concentration range of $(0.02-1 \mu \mathrm{g} / \mathrm{ml})$ and amphotericin $\mathrm{B}$ at concentration range of $(0.5-3 \mu \mathrm{g} / \mathrm{ml})$ were used as standard antibacterial and antifungal positive controls. The final volume in each well was $200 \mu \mathrm{l}$. The plate was covered with a sterile plate sealer $80 / 140 \mathrm{~mm}$ (Greiner bio-one, Germany). For bacteria, plates were incubated for $24 \mathrm{~h}$ at $37^{\circ} \mathrm{C}$ while for fungi; plates were incubated for $3-5$ days at $30-35^{\circ} \mathrm{C}$. The growth of bacteria and fungi was determined by absorbance values at $600 \mathrm{~nm}$ and $530 \mathrm{~nm}$ respectively using fully automated Microplate Spectrophotometer (Bio-Rad Laboratories, Hercules, Canada).

To confirm MIC and to establish minimum bactericidal (MBC) and minimum fungicidal (MFC) concentrations, 10 $\mu 1$ of each culture medium for bacteria and fungi with no visible growth were removed from each well and inoculated, in triplicates, on nutrient agar and sabouraud dextrose agar plates, respectively. After incubation for $24 \mathrm{~h}$ at $37^{\circ} \mathrm{C}$, for bacteria, and $3-5$ days at $30-35^{\circ} \mathrm{C}$, for fungi, the number of surviving organisms was determined. $\mathrm{MBC}$ and $\mathrm{MFC}$ are defined as the lowest extract concentration at which $99.9 \%$ of the microorganism is killed. The extract tested in this study was screened three times for each organism.

\section{Scanning Electron Microscope (SEM) and Transmission Electron Microscope (TEM) Observations}

Scanning electron microscope observations were carried out on S. aureus (ATCC 29247) and E.coli (ATCC 25922) as an example for the extract effect on bacterial cells of Gram negative and Gram positive bacteria. One milliliter of $10^{8} \mathrm{CFU} / \mathrm{ml}$ of S.aureus or E.coli bacterial suspensions were incubated with the extract at concentraion of $100 \mathrm{mg} / \mathrm{ml}$ for $24 \mathrm{~h}$ at $37^{\circ} \mathrm{C}$. A $10 \%$ DMSO-treated culture was used as a negative control. The control and the extract treated cells were fixed in 4\% glutaraldehyde (Sigma, Steinheim, Germany) and later postfixed in 1\% osmium tetraoxide (Sigma, Steinheim, Germany) and they were later washed by $0.1 \mathrm{M}$ sodium cacodylate buffer, pH 7.4 (Sigma, Steinheim, Germany). After eliminating the remaining osmium tetraoxide, the samples were dehydrated in a graduated acetone (Merck,
Darmstadt, Germany) series (35 to 100\%). Each step was performed for about 10 to $15 \mathrm{~min}$ at room temperature.

The specimens were then dried in the critical dryer (Baltec, CPD 030). The dried specimens were mounted onto stubs by double-sided carbon tape. The specimens were coated with a thin layer of gold by a Polaron SC 502 sputter coater, and were examined in the Scanning Electron Microscope (Philips, XL30 ESEM).

For the transmission electron microscope observation, after the dehydration step, the fixed cells were embedded with Epon and the small blocks of bacteria were cut with an ultramicrotome (Reichert Jung Ultracut-S, Leica). The ultra thin sections were then analyzed using TEM (Philips, EM400 HMG).

\section{Statistical Analysis}

The disc diffusion assay was conducted in triplicates in three independent experiments. Therefore, the inhibition zone was expressed as mean SD. SPSS software version 12.0.0.2 was used.

\section{RESULTS}

\section{Disc Diffusion Assay for Bacteria}

Qualitative and quantitative results were obtained by the inhibition zone and zone diameter, respectively (Table 1). The methanol extract of $B$. oleracea showed significant inhibitory effect against the growth of both Gram negative and Gram positive bacteria. The mean inhibition zone for the Gram positive bacteria ranged from 7 to $17 \mathrm{~mm}$ indicating a remarkable antibacterial effect when compared with that of streptomycin, the positive control, which ranged from 0 to $18 \mathrm{~mm}$. Interestingly, the methanol crude extract for $B$. oleracea exerted an exclusive antibacterial effect against the problematic bacteria MRSA while, interestingly, the antibacterial effect of the positive control, streptomycin, was zero. In contrast to all previous studies known in the field of antibacterial natural products, the methanol crude extract of $B$. oleracea in the current study revealed highly significant antibacterial effect against the entire tested Gram negative bacteria (12-20 $\mathrm{mm}$ zone of inhibition) whereas the standard drug, streptomycin, exhibited zone of inhibition ranged from 11-19 mm only.

\section{Microdilution Assay for Bacteria}

The MIC of the Gram positive bacteria was $100 \mathrm{mg} / \mathrm{ml}$, including MRSA, while the confirmatory test, MBC, was $400 \mathrm{mg} / \mathrm{ml}$ except for B. subtilis was $200 \mathrm{mg} / \mathrm{ml}$ (Table 2). On the other hand, the MIC of the Gram negative bacteria was between $100-400 \mathrm{mg} / \mathrm{ml}$ while the confirmatory test, MBC, was between 200-500 mg/ml (Table 2). The logarithmic OD values were demonstrated for each tested bacterium. OD values decreased in a dose dependent manner reflecting the decrease took place in the bacterial growth (Fig. $1 \& 2$ ). The findings of the $\mathrm{MIC}$ and $\mathrm{MBC}$ were in agreement with the findings obtained by the primary screening test, disc diffusion assay. Hence, disc diffusion, MIC, and MBC assays together provided evidence that the $B$. oleracea extract was highly effective as antimicrobial agent against both the tested Gram negative and positive bacteria. 


\section{Antimicrobial Assays for Fungi}

In contrast to the effective antibacterial activity revealed by the crude methanol extract of red cabbage leaves, the extract did not demonstrate effective antifungal activity against most of the tested fungi. Nevertheless, the extract showed an unprecedented potent antifungal activity against two of important human fungal pathogens namely, T. rubrum [18] and A. terreus [19] at concentrations $(700 \mathrm{mg} / \mathrm{ml})$ and $(500,700$ $\mathrm{mg} / \mathrm{ml}$ ) respectively (Table 3 ). The extract under these two concentrations showed clear zone of inhibition. To confirm the antifungal activity, both MIC and MFC were done which confirmed the antifungal activity against these two fungi. The MIC of the extract against $T$. rubrum and $A$. terreus was $75 \mathrm{mg} / \mathrm{ml}$ while the MBC of the extract was 300 and $150 \mathrm{mg} / \mathrm{ml}$, respectively (Table 4). The growth inhibition was dose dependent and was reflected by the decrease of

Table 1. Antibacterial Activity of B.oleracea Methanol Extract by Disc diffusion Method

\begin{tabular}{|c|c|c|c|c|c|}
\hline \multicolumn{2}{|c|}{ Microorganisms } & \multicolumn{4}{|c|}{ Inhibition Zone in Diameter (mm) } \\
\hline \multirow[t]{2}{*}{ Bacterial species } & \multirow[t]{2}{*}{ Number of strains } & \multicolumn{2}{|c|}{$\begin{array}{l}\text { B.oleracea methanol extract } \\
\qquad(\mathrm{mg} / \mathrm{ml})\end{array}$} & \multirow[t]{2}{*}{$\begin{array}{l}\text { Negative control } \\
\qquad\left(\mathrm{MeOH}^{*}\right)\end{array}$} & \multirow[t]{2}{*}{$\begin{array}{c}\text { Positive control } \\
\text { Streptomycin } 10 \mu \mathrm{g} / \mathrm{disc}\end{array}$} \\
\hline & & 200 & 500 & & \\
\hline Staphylococcus aureus & 2 (clinical isolate) & - & $11.5 \pm 2.5$ & $-\dagger$ & $18 \pm 0.4$ \\
\hline S. aureus & 1 (ATCC 29247 stain) & - & $11 \pm 1.3$ & - & $17 \pm 0.8$ \\
\hline $\mathrm{MRSA}^{\mathrm{a}}$ & 1 (clinical isolate) & - & $7 \pm 0.5$ & - & - \\
\hline Bacillus subtilis & 1 (isolate) & $7 \pm 0.3$ & $17 \pm 0.8$ & - & $18 \pm 1.1$ \\
\hline Escherichia coli & 1(clinical isolate) & $12 \pm 0.9$ & $19 \pm 2.1$ & - & $16 \pm 0.9$ \\
\hline E.coli & 1 (ATCC 25922 strain) & $15 \pm 1.1$ & $20 \pm 1.0$ & - & $11 \pm 0.3$ \\
\hline E.coli & 1 (ATCC 35218 strain) & $15 \pm 0.8$ & $20 \pm 1.7$ & - & $16 \pm 0.5$ \\
\hline E.coli $\mathrm{O} 157: \mathrm{H} 7$ & 1 (isolate) & $13 \pm 1.2$ & $17 \pm 0.4$ & - & $18 \pm 0.8$ \\
\hline Pseudomonas aeruginosa & 1 (clinical isolate) & $12 \pm 0.6$ & $19 \pm 0.6$ & - & $18 \pm 1.0$ \\
\hline Klebsiella pneumoniae & 1 (clinical isolate) & $8 \pm 0.5$ & $15 \pm 0.5$ & - & $19 \pm 0.7$ \\
\hline $\begin{array}{l}\text { Salmonella enterica } \\
\text { serovar Typhimurium }\end{array}$ & 1 (ATCC 25241 strain) & $18 \pm 1.3$ & $18 \pm 0.6$ & - & $15 \pm 0.5$ \\
\hline
\end{tabular}

*: MeOH: methanol, $\dagger:(-)$ means no growth inhibition zone, ${ }^{a}$ : Methicillin-resistant Staphyloccocus aureus.

Table 2. The MIC and MBC Values Against the Tested Bacteria by the Microdilution Method

\begin{tabular}{|c|c|c|c|c|c|c|c|}
\hline \multirow[t]{2}{*}{ Bacterial Species } & \multirow[t]{2}{*}{ Number of Strains } & \multirow[t]{2}{*}{$\begin{array}{c}\mathrm{MIC}^{*} \\
(\mathrm{mg} / \mathrm{ml})\end{array}$} & \multirow[t]{2}{*}{$\begin{array}{c}\mathrm{MBC}^{\dagger} \\
(\mathrm{mg} / \mathrm{ml})\end{array}$} & \multirow[t]{2}{*}{$\begin{array}{c}\text { MBC: } \\
\text { MIC Ratio }\end{array}$} & \multirow[t]{2}{*}{$\begin{array}{c}\text { Antibacterial } \\
\text { Mode }\end{array}$} & \multicolumn{2}{|c|}{$\begin{array}{l}\text { Positive Control Streptomy- } \\
\text { cin } \\
\mathrm{mg} / \mathrm{ml}\end{array}$} \\
\hline & & & & & & MIC & MBC \\
\hline Staphylococcus aureus & 2 (clinical isolate) & 100 & 400 & $4: 1$ & Bacteristatic & 0.065 & 0.104 \\
\hline S. aureus & 1 (ATCC 29247 stain) & 100 & 400 & 4: 1 & Bacteristatic & 0.06 & 0.1 \\
\hline MRSA $^{a}$ & 1 (clinical isolate) & 100 & 400 & $4: 1$ & Bacteristatic & $-{ }^{\mathrm{b}}$ & - \\
\hline Bacillus subtilis & 1 (clinical isolate) & 100 & 200 & 2: 1 & Bactericidal & 0.04 & 0.08 \\
\hline Escherichia coli & 1(clinical isolate) & 100 & 200 & $2: 1$ & Bactericidal & 0.05 & 0.1 \\
\hline E.coli & 1 (ATCC 25922 strain) & 100 & 400 & $4: 1$ & Bacteristatic & 0.045 & 0.09 \\
\hline E.coli & 1 (ATCC 35218 strain) & 300 & 400 & $1.3: 1$ & Bactericidal & 0.042 & 0.08 \\
\hline E.coli $\mathrm{O} 157: \mathrm{H} 7$ & 1 (isolate) & 200 & 400 & $2: 1$ & Bactericidal & 0.049 & 0.09 \\
\hline Pseudomonas aeruginosa & 1 (clinical isolate) & 100 & 200 & $2: 1$ & Bactericidal & 0.047 & 0.08 \\
\hline Klebsiella pneumoniae & 1 (clinical isolate) & 100 & 400 & $4: 1$ & Bacteristatic & 0.05 & 0.085 \\
\hline $\begin{array}{l}\text { Salmonella enterica } \\
\text { serovar Typhimurium }\end{array}$ & 1 (ATCC 25241 strain) & 400 & 500 & $1.25: 1$ & Bactericidal & 0.048 & 0.082 \\
\hline
\end{tabular}

*: minimum inhibitory concentration, $\dagger$ :minimum bactericidal concentration, ${ }^{\mathrm{a}}$ : Methicillin-resistant Staphyloccocus aureus, ${ }^{\mathrm{b}}$ : (-) means no growth inhibition detected. 


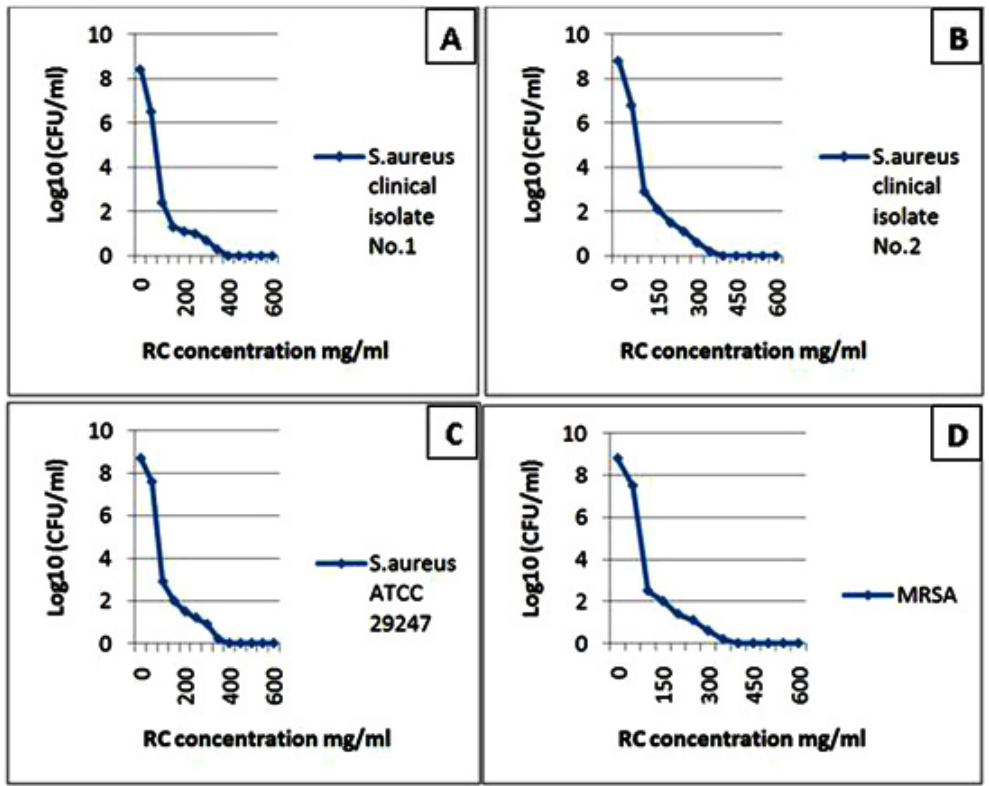

Fig. (1). The diagrams reflect the decrease in the bacterial growth (A: Staphylococcus aureus clinical isolate No. 1, B: Staphylococcus aureus clinical isolate No. 2, C: Staphylococcus aureus ATCC 29247 and D: Methicilline - resistant Staphylococcus aureus) which demonstrated by $\log 10$ measured by microdilution assay. The decrease in bacterial growth resulted from red cabbage (RC) methanol crude extract treatment in different concentrations. These four bacteria showed no visible growth around the $6 \mathrm{~mm}$ disc impregnated in RC methanol crude extract at $500 \mathrm{mg} / \mathrm{ml}$ concentration in the disc diffusion test.

OD values which were demonstrated in logarithmic manner (Fig. 3).

\section{Mode of Antimicrobial Action}

The nature of the antibacterial effect of the extract with regard to inhibition/killing of tested bacteria is important. The MBC: MIC ratio for bacteria or MFC: MIC for fungi is used to specify the nature of the antimicrobial effect against any given pathogen [20]. When the MBC: MIC or MFC: MIC ratio of a pathogen is between 1:1 to $2: 1$, the chemical substance is considered as bactericidal or fungicidal against that pathogen [20]. On the other hand, if the ratio was $>2: 1$, the mode of antimicrobial action is more likely to be bacteristatic or fungistatic. Therefore, MBC: MIC or MFC: MIC ratio was calculated for each bacterial or fungal pathogen, respectively. It was found that the tested extract of red cabbage exerted a clear bactericidal effect against 6 isolates of bacteria while it exerted bacteristatic effect against 5 isolates only (Table 2). For fungi, the extract exerted fungicidal effect against $A$. terreus and fungistatic against $T$. rubrum (Table 4).

\section{SEM and TEM Electron Microscope Observations}

The antibacterial effect of red cabbage extract on $S$. aureus and E. coli was seen clearly by SEM. After exposing $S$. aureus and E. coli to $100 \mathrm{mg} / \mathrm{ml}$ of the methanol extract, the cells were collapsed and became sticky, almost seen like a shrunken cells when compared to control cells (Fig. 4). In addition, detachment of the cell membrane of the tested bacterial cells was seen in response to the added red cabbage extract. Therefore, the antibacterial effect of red cabbage extract, observed by TEM, was demonstrated as clear morphorlogical changes in the treated cells (Fig. 5).

\section{DISCUSSION}

The wide spread of MDR microbes raises the need for new, cheap, effective, and safe drugs. One of the best candi- dates to address this need appears to be the natural resources. Before being considered as a food, cabbage was valued and used for medicinal purposes in treating headache, gout, diarrhea and peptic ulcers [21]. Among the substances that seem to be responsible for these properties are polyphenols [22]. Red cabbage is a rich source of phenolic compounds, mainly anthocyanins which are the most abundant class [23].

Previous studies reported that methanol was the best solvent for the consistent extraction of antimicrobial substances from medicinal plants compared to other solvents such as water, ethanol, or hexane [24]. For this reason, methanol was used in this study to extract the active antimicrobial components from red cabbage leaves. The findings of the current study demonstrated some novel and significant antimicrobial activities against the tested bacteria and fungi. Remarkable zones of inhibition were observed around the discs of the red cabbage extract in nutrient agar plates inoculated with Gram negative (12-20 $\mathrm{mm}$ in diameter) and Gram positive bacteria (7-17 $\mathrm{mm}$ in diameter). This finding seems to be unique for the current study when compared with previous studies which were conducted to test the antibacterial activity of different natural products. These reports revealed that their extracts were effective against Gram positive rather than Gram negative bacteria and they attributed this variation to the dissimilarity between Gram negative and Gram positive cell walls which makes Gram negative more resistant to many antibacterial agents [25]. This provides evidence that red cabbage extract possesses different antibacterial components exerting different mechanisms of action. The wide spectrum of antibacterial effects of the red cabbage extract in the current study might be attributed to the acid methanol procedure of extraction which is suitable for extracting all fractions efficiently.

In fact, only two studies were found to be conducted on the antibacterial effect of red cabbage extract worldwide. A 


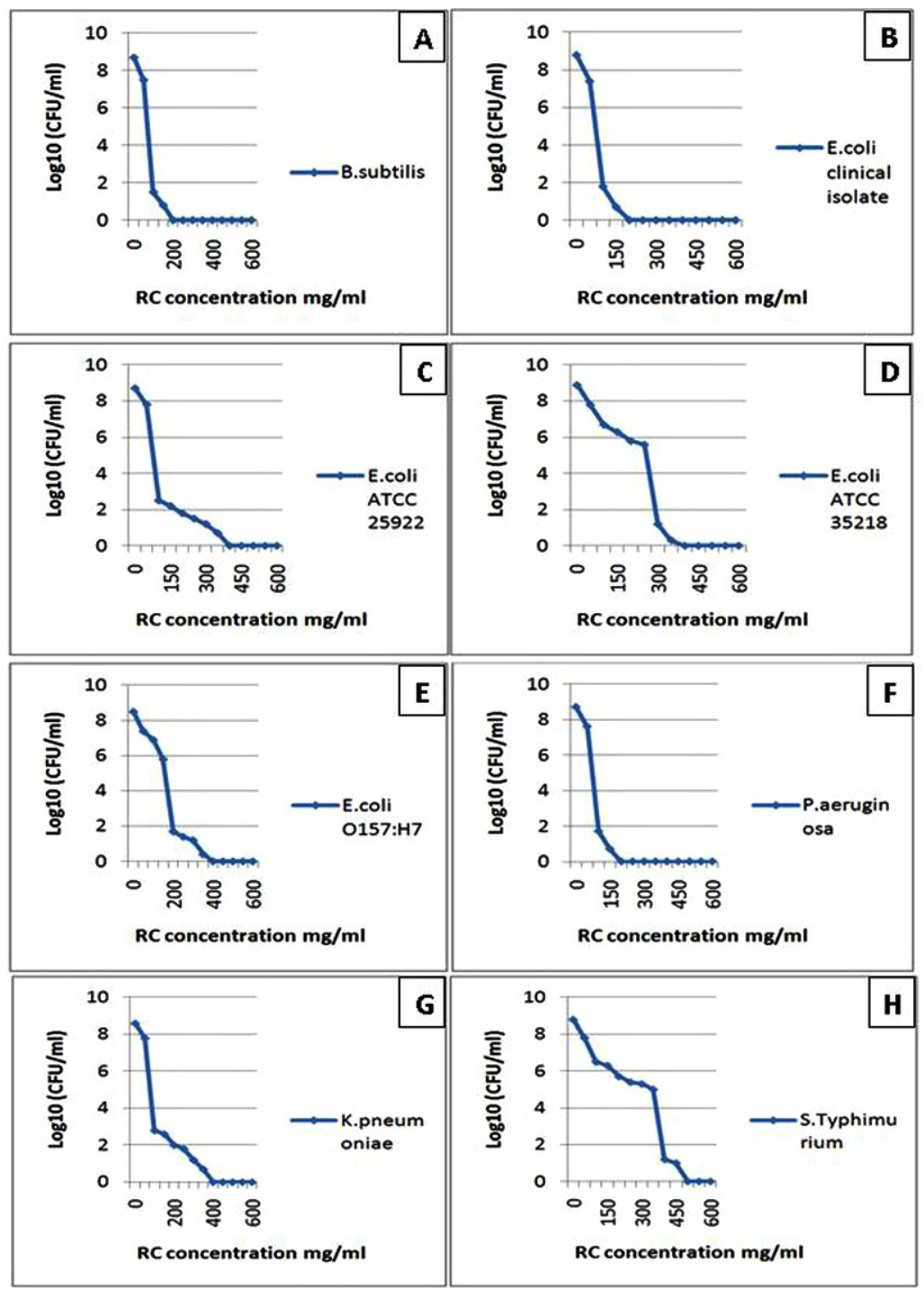

Fig. (2). The diagrams reflect the decrease in the bacterial growth (A: Bacillus subtilis, B: Escherichia coli clinical isolate, C: Escherichia coli ATCC 25922, D: Escherichia coli ATCC 35218, E: Escherichia coli O157:H7, F: Pseudomonas aeruginosa, G: Klebsiella pneumoniae and H: Salmonella enterica serovar Typhimurium ATCC 25241) which demonstrated by log 10 measured by microdilution assay. The decrease in bacterial growth resulted from red cabbage (RC) methanol crude extract treatment in different concentrations. These eight bacteria showed no visible growth around the $6 \mathrm{~mm}$ disc impregnated in RC methanol crude extract at $200 \mathrm{mg} / \mathrm{ml}$ concentration in the disc diffusion test.

study done by Lee and his colleagues in 2003 found that red cabbage juice has mild activity against Staphylococcus epidermidis but not against Klebsiella pneumoniae [12], while Park and his colleagues in 2004 found that the methanol red cabbage fractions seem to be active against $B$. subitilis, $E$. coli and, with mild action, against $P$. aeruginosa [13]. In the current study the effect of red cabbage extract was studied on many bacterial species, including bacteria not researched before such as; S. aureus, MRSA, E. coli O157:H7, and Salmonella enterica serovar Typhimurium. Besides, $P$. aeruginosa and $K$. pneumoniae were researched before but, unlike the results of the current study, a study revealed a very mild response and the second one revealed no response at all to red cabbage extract $[12,13]$.

In the current study, the considerable inhibition zone gained from the red cabbage extract at concentration 500 $\mathrm{mg} / \mathrm{ml}$ against MRSA, $7 \mathrm{~mm}$ versus $0 \mathrm{~mm}$ of standard drug, and $S$. aureus, about $11 \mathrm{~mm}$ versus $17-18 \mathrm{~mm}$ of standard drug, was highly promising. The MIC for MRSA and $S$. aureus bacteria was $100 \mathrm{mg} / \mathrm{ml}$ while the $\mathrm{MBC}$ was 400 $\mathrm{mg} / \mathrm{ml}$. Therefore, the MBC: MIC ratio was 4: 1 indicating that the potent anti-MRSA and anti-S. aureus effect was more likely bacteristatic in nature. A recent study found that hospitals across the United States and around the world are fighting the escalation of drug-resistant infections [26]. Furthermore, an increase in community-associated methicillinresistant Staphylococcus aureus (CA-MRSA) infections have been reported in many literatures [27]. Most of these infections are severe and life-threatening. Taken into account that the tested MRSA was found of intermediate response to vancomycin (VISA), the antibacterial agent(s) in red cabbage extract responsible for this action must be a top priority for the study and discovery. It is worth mentioning that MRSA VISA strains present a thickening of the cell wall which is believed to deplete the vancomycin available to kill the bacteria which worries many physicians and microbiologists on 
Table 3. Antifungal Activity of B.oleracea Methanol Extract by Disc Diffusion Method

\begin{tabular}{|c|c|c|c|c|c|c|}
\hline \multicolumn{2}{|c|}{ Microorganisms } & \multicolumn{5}{|c|}{ Inhibition Zone in Diameter (mm) } \\
\hline \multirow[t]{2}{*}{ fungal species } & \multirow[t]{2}{*}{ Number of strains } & \multicolumn{3}{|c|}{$\begin{array}{l}\text { B.oleracea methanol extract } \\
\qquad(\mathrm{mg} / \mathrm{ml})\end{array}$} & \multirow[t]{2}{*}{$\begin{array}{l}\text { Negative control } \\
\qquad\left(\mathrm{MeOH}^{*}\right)\end{array}$} & \multirow[t]{2}{*}{$\begin{array}{c}\text { Positive control } \\
\text { Amphotericin B }(10 \mu \mathrm{g} / \mathrm{disc})\end{array}$} \\
\hline & & 200 & 500 & 700 & & \\
\hline Trichophyton rubrum & 1 (ATCC 11990) & - & - & $8 \pm 0.3$ & $-\dagger$ & $11 \pm 0.5$ \\
\hline Microsporum canis & 1 (ATCC 8137) & - & - & - & - & $10 \pm 0.6$ \\
\hline Aspergillus niger & 1 isolate & - & - & - & - & $18 \pm 1.0$ \\
\hline A.terreus & 1 (ATCC strain 20542) & - & 10 & $11 \pm 0.5$ & - & $10 \pm 0.8$ \\
\hline A.oryzae & 1 isolate & - & - & - & - & $8 \pm 0.6$ \\
\hline Paecilomyces variotti & 1 isolate & - & - & - & - & $18 \pm 1.0$ \\
\hline Phanerochaete chrysosporium & 1 isolate & - & - & - & - & $19 \pm 1.3$ \\
\hline Trichoderma sp. & 1 isolate & - & - & - & - & - \\
\hline Trichoderma & harzianum 1 (ATCC strain 20671) & - & - & - & - & $10 \pm 0.7$ \\
\hline Trichoderma atroviride & 1 (ATCC strain 74058) & - & - & - & - & - \\
\hline
\end{tabular}

*: MeOH: methanol. $\dagger$ : (-) means no growth inhibition zone.

Table 4. The MIC and MFC Values Against the Tested Fungi by the Microdilution Method

\begin{tabular}{|c|c|c|c|c|c|c|}
\hline fungal Species & Number of Strains & $\begin{array}{c}\text { MIC }^{*} \\
(\mathbf{m g} / \mathbf{m l})\end{array}$ & $\begin{array}{c}\text { MFC }^{\dagger} \\
(\mathbf{m g} / \mathbf{m l})\end{array}$ & $\begin{array}{c}\text { MFC: MIC } \\
\text { Ratio }\end{array}$ & $\begin{array}{c}\text { Antifungal } \\
\text { Mode }\end{array}$ & $\begin{array}{c}\text { Positive Control Amphotericin } \\
\text { B } \\
\mu \mathbf{g} / \mathbf{m l} \\
\text { MBC }\end{array}$ \\
\hline \hline Trichophyton rubrum & 1 (ATCC 11990) & 75 & 300 & $4: 1$ & Fungistatic & 2 \\
\hline Aspergillus terreus & 1 (ATCC strain 20542) & 75 & 150 & $2: 1$ & Fungicidal & 2.8 \\
\hline
\end{tabular}

*: minimum inhibitory concentration, $\uparrow$ :minimum fungicidal concentration.

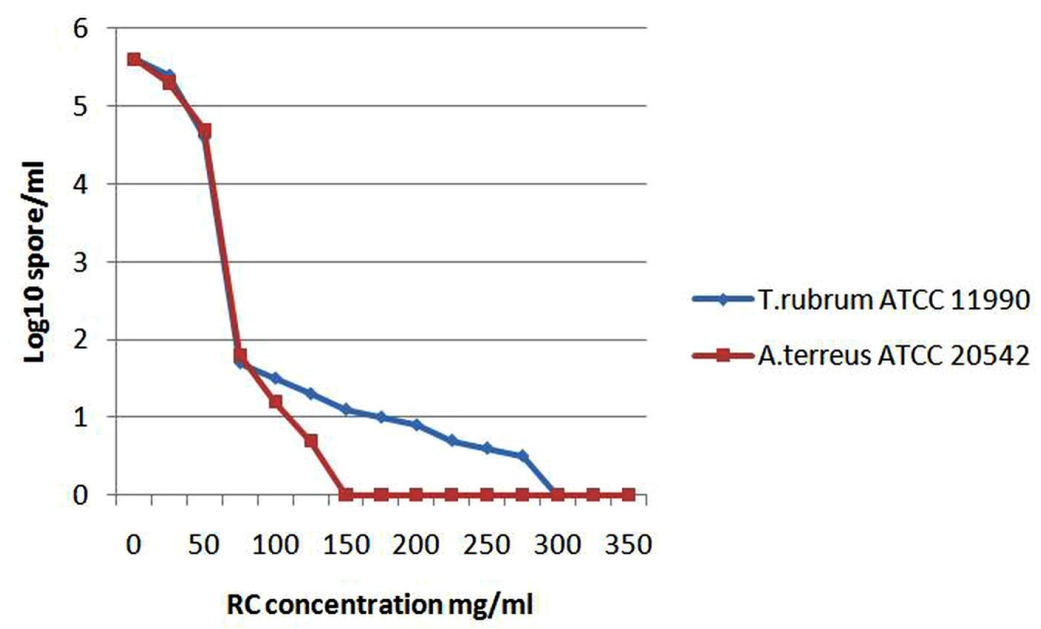

Fig. (3). The diagram demonstrates the growth inhibtion of the sensitive fungi expressed by $\log 10$ which detected by the microdilution assay after incubation with red cabbage (RC) methanol crude extract in different concentrations.

the near future prospects of the current anti-MRSA therapies [28]. Furthermore, the current red cabbage anti-MRSA activity and its underlying mechanism of action seem novel and different from other known antibiotics. Accordingly, the discovery of natural, effective, and cheap drug against this resistant bacterium might be considered as a breakthrough solution for this problem all around the world. 

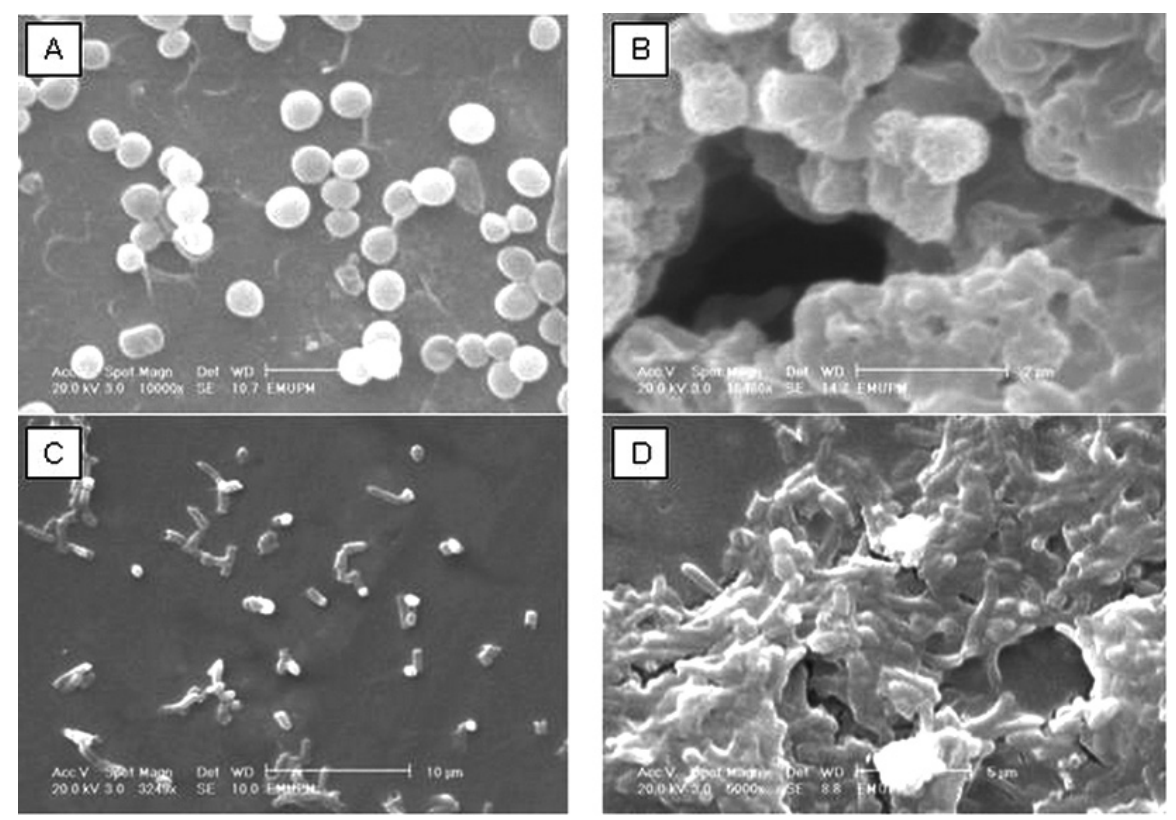

Fig. (4). The scanning electron microscope study of red cabbage methanol extract showing the cytological changes in Staphylococcus aureus ATCC 29247 cells: (A) control cells (B) treated cells and Escherichia coli ATCC 25922 cells: (C) control cells (D) treated cells.
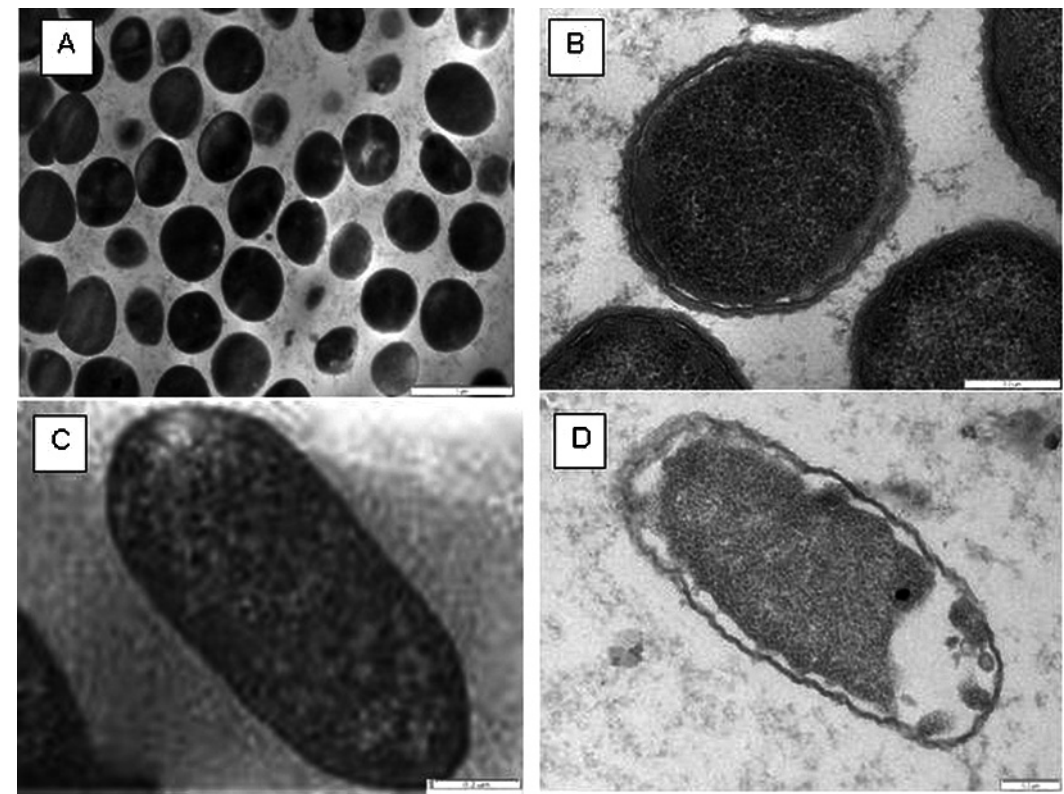

Fig. (5). The transmission electron microscope study of red cabbage methanol extract showing the cytological changes in Staphylococcus aureus ATCC 29247 cells: (A) control cells: magnification 21.500k (B) treated cells: magnification 100.000k and Escherichia coli ATCC 25922 cells: (C) control cells: magnification $60.000 \mathrm{k}$ (D) treated cells: magnification $60.000 \mathrm{k}$.

Recently, E. coli O157:H7 was shown to be highly resistant to different antibiotics which are commonly used by clinicians and veterinarians for the treatment of infections with Gram-negative bacteria [29]. For this reason, the used isolate of EHEC O157:H7 in the current study was selected to be highly resistant isolate against four antibiotics. The antibacterial activity results of the of red cabbage extract against E.coli $\mathrm{O} 157: \mathrm{H} 7$ was remarkable. The inhibition zone was about $17 \mathrm{~mm}$ at concentration $500 \mathrm{mg} / \mathrm{ml}$ of the extract which is only $1 \mathrm{~mm}$ less than the diameter of the standard antibiotic, streptomycin. Moreover, the MBC: MIC ratio was $2: 1$, revealing potent bactericidal effect of red cabbage against this notorious bug. Therefore, the extract of red cab- bage can be considered as a novel source of a new candidate antibacterial agent for both human and animal E. coli O157:H7 diseases.

For $P$. aeruginosa, it is known to be resistant to high concentrations of salts and dyes, weak antiseptics, and many commonly used antibiotics [30]. The isolate of $P$. aeruginosa used in the current study was selected to be highly resistant against 6 different antibiotics. Despite its bad history in antibiotic sensitivity, interestingly, the red cabbage extract of the current study showed $19 \mathrm{~mm}$ inhibition zone which was $1 \mathrm{~mm}$ larger than that of streptomycin itself. Moreover, MBC (200): MIC (100) $\mathrm{mg} / \mathrm{ml}, 2: 1$ ratio, indicated that the 
red cabbage extract exerted a very potent bactericidal effect at lower concentration of extract than in most other tested bacteria.

For K. pneumoniae, it was found that it has developed several strains resistant to several antibiotics. These strains are known as extended-spectrum B-lactamase (ESBL)producing K. pneumoniae [31]. Similarly, Salmonella enterica serovar Typhimurium began to show serious antimicrobial resistance patterns worldwide via ESBL leading to resistance against ampicillin, aminoglycosides, and trimethoprim-sulfamethoxazole [32]. Interestingly, a remarkable antibacterial effect, bacteristatic and bactericidal, was found by the red cabbage extract against $K$. pneumoniae and $S$. enterica serovar Typhimurium. The antibacterial effect of the extract against $S$. enterica serovar Typhimurium was unique in that MBC: MIC ratio was the lowest one among all tested bacteria, 1.25:1. Besides, the inhibition zone was the same for both 200 and $500 \mathrm{mg} / \mathrm{ml}$ concentrations of the extract and larger than that of streptomycin. In fact, the $15 \mathrm{~mm}$ inhibition zone indicates a very powerful bactericidal effect of red cabbage extract against this bacterium.

Collectively, three MDR bacteria used in the current study were resistant to 15 powerful antibiotics that belong to 8 different groups of antibiotics. These 8 groups belong to 5 common modes of action including cell wall targeting penicillin and $3^{\text {rd }}$ and $4^{\text {th }}$ generations of cephalosporin's, $30 \mathrm{~S}$ ribosomal subunit targeting glycopeptides and polyketide, 50S ribosomal subunit targeting lincosamide and macrolides, DNA synthesis-inhibiting fluoroquinolones, and enzymes competitors sulfonamides. Since, red cabbage leaves extract exerted a powerful bactericidal effect against two MDR bacteria and exerted a bacteriostatic effect against one MDR bacteria, the antimicrobial effect of the red cabbage leaves extract seems to bypass the most common pathways of antibiotics resistance. Therefore, this provided a clue on the high possibility for the presence of novel antimicrobial compound(s) in red cabbage extract that might not share the same mode of action with the above mentioned antibiotics or at least have some modified interactions of the same pathway.

A. terreus infections have become a growing concern in the past few years as a causative agent of invasive aspergillosis [33]. This infection has become resistant to most common antifungal agents used to treat aspergillosis [34]. In addition, $T$. rubrum is the most common dermatophyte species. It is a major concern because feet and nail infections caused by this organism are extremely difficult to cure [18]. In addition, resistance to most of the commercially available antifungal agents was recorded [35]. The use of red cabbage extract in the current study demonstrated significant zones of inhibition in the fungal growth of $T$. rubrum, $8 \mathrm{~mm}$ versus $11 \mathrm{~mm}$ of standard drug, and A. terreus, $11 \mathrm{~mm}$ versus 10 $\mathrm{mm}$ of standard drug. Hence, it was interesting that the inhibition zone of $A$. terreus by red cabbage extract at concentration $700 \mathrm{mg} / \mathrm{ml}$ was larger than that produced by the standard drug. Moreover, the MFC: MIC ratio revealed that red cabbage extract is fungicidal against $A$. terreus, ratio $2: 1$, and fungistatic against $T$. rubrum, ratio 4:1. No previous study recorded such antifungal activity of red cabbage ex- tract against any fungi. It was only one study revealed a negative result of the red cabbage extract fraction against $A$. oryzae [13], and it is in confirmatory with the result of this study. Both $T$. rubrum and A. terreus are important human pathogens and cause serious health problems all around the world. Therefore, the discovered antifungal effect in this study might be considered as a prelude to discover new antifungal agents to those two problematic pathogenic fungi.

The mixture of phenolic compounds acts synergistically better than its individual components separately [36]. Studies showed that the mixture of anthocyanins (ATH) extracted from red cabbage possessed high antioxidant properties and these studies suggested the presence of the protective action of this extract [37]. This synergistic effect of the phenolic compounds in red cabbage extract, particularly anthocynins mixture, may explain the potent antibacterial action and, for the first time, the significant antifungal action manifested in the current study. Studies revealed that the antioxidant activity of the ATH-rich extract from red cabbage leaves is high, about 33 Trolox equivalents (TE) per $\mathrm{g}$ of fresh matter and 328 TE per g of dry matter, whereas, in fruits such as blackberries, cranberries, and strawberries, TE values ranged from 35 to 162 per g of dry matter [38, 39]. Taking into account such high antioxidant capacity of the ATH-rich extract from red cabbage leaves, we suppose that the potential antimicrobial activity may be due to this subclass of flavonoids. Interestingly, recent research showed that, through overlapping or complementary effects, the complex mixture of phytochemicals in fruits and vegetables provides a better protective effect on health than single phytochemicals [40]. Therefore, the complex components of red cabbage extract needs to be scrutinized in depth in order to find the best mixture of effective components that had role in the currently shown antibacterial and antifungal actions. This will be necessary to translate the findings of this study into novel commercial antibiotics and antifungal drugs.

Furthermore, one of the interesting points regarding red cabbage leaves extract is its $\mathrm{pH}$ range of 6.8 to 7.2. This neutral $\mathrm{pH}$ eliminates the possibility that the antimicrobial effect of this extract is attributed to its ability to create an acidic environment. It was proposed that the possible mechanism of antimicrobial activity by some of the phenolic containing extracts is by creating an acidic environment that causes the bacterial cell membrane disruption [41]. Therefore, the substantial results obtained in the current study may be due, in part, to the ATH subclass of flavonoids. Many studies proposed various mechanisms to account for the antioxidant ability of ATH. They include radical scavenging ability, metal chelating property, hydrogen donating ability, complex formation with DNA and direct binding to proteins [42-44]. These various mechanisms alone or together may attribute to the potent antimicrobial activity we had obtained.

Many studies attempted to investigate the effect of crude plants extracts on different bacteria to support the antibacterial activity they gained from the disc diffusion and the microdilution assays. In this study the electron microscopic observations for both SEM and TEM demonstrated clearly the antibacterial effect of the methanol extract of red cabbage on bacterial cells. There were clear morphological changes with shrunken and collapsed cells of the teated bacteria. This 
could be due to the leak in the cell wall or perhaps some alteration in the membrane permeability. These findings augmented the antibacterial prospects for the crude methanol extract of the red cabbage which give clue that crude methanol extract of the red cabbagea is a promising antimicrobial agent.

Taken together, it was concluded that the red cabbage extract using acid methanol solvent showed a potent antimicrobial effect against the tested Gram negative, Gram positive bacteria, and fungi. Most interestingly, for the first time, red cabbage extract showed remarkable antibacterial effect against MRSA, S. aureus, E. coli O157:H7, S. enterica serovar Typhimurium, and $K$. pneumoniae as well as remarkable antifungal effect against $T$. rubrum and A. terreus. Moreover, the bacterial species that weakly responded to red cabbage extract in previous studies, namely $P$. aeruginosa, were shown to be strongly eradicated by the bactericidal effect of the extract of the current study. This potent effect may be due to the high level of red cabbage active polyphenols, precisely, the anthocyanins. The in vitro results of this study on the efficacy of red cabbage crude extract as antimicrobial agent may give confidence about its activity if used in vivo. Considering the safety of a natural product extract, red cabbage extract could be a promising antimicrobial agent if used in vivo.

\section{CONCLUSION}

The findings of the current study unveiled a novel, powerful, and broad spectrum antimicrobial activity of red cabbage leaves extract against a large number of human and animal pathogenic microbes including MDR bacteria, nonMDR bacteria, and fungi. Further investigations on the active antimicrobial components in the red cabbage methanol crude extract are required to provide the pharmaceutical companies with cheap and effective antimicrobial agent.

\section{REFERENCES}

[1] Cowan MM. Plant products as antimicrobial agents. Clin Microbiol Rev 1999; 12: 564-82.

[2] Tateda K, Ishii Y. Multiple-drug resistant bacteria: how do they come to exist, spread, and express their pathogenicity?. Nippon Naika Gakkai Zasshi 2003; 92: 2097-103.

[3] Gautam R, Saklani A, Jachak SM. Indian medicinal plants as a source of antimycobacterial agents. J Ethnopharmacol 2007; 110: 200-34.

[4] Simonetti P, Gardana C, Pietta P. Plasma levels of caffeic acid and antioxidant status after red wine intake. J Agric Food Chem 2001; 49: $5964-68$

[5] Sultana B, Anwar F. Flavonols (kaempeferol, quercetin, myricetin) contents of selected fruits, vegetables and medicinal plants. Food Chemistry 2008; 108: 879-84.

[6] Harvey AL. Natural products in drug discovery. Drug Discov Today 2008; 13: 894-901.

[7] Singh J, Upadhyay AK, Bahadur A, Singh B, Singh KP, Rai M. Antioxidant phytochemicals in cabbage (Brassica oleracea $\mathrm{L}$. var. capitata). Sci Hortic-Amsterdam 2006; 108: 233-7

[8] Kassie F, Uhl M, Rabot S, et al. Chemoprevention of 2-amino-3methylimidazo[4,5-f]quinoline (IQ)-induced colonic and hepatic preneoplastic lesions in the F344 rat by cruciferous vegetables administered simultaneously with the carcinogen. Carcinogenesis 2003; 24: 255-261.

[9] Walters DG, Young PJ, Agus C, et al. Cruciferous vegetable consumption alters the metabolism of the dietary carcinogen 2-amino1-methyl-6-phenylimidazo[4,5-b]pyridine (PhIP) in humans. Carcinogenesis 2004; 25: 1659-69.

[10] Lin JY, Lia CY, Hwang IF. Characterisation of the pigment components in red cabbage (Brassica oleracea L. var. capitata) juice and their anti-inflammatory effects on LPS-stimulated murine splenocytes. Food Chemistry 2008; 109: 771-81

[11] Kataya HA, Hamza AA. Red Cabbage (Brassica oleracea) Ameliorates Diabetic Nephropathy in Rats. Evid Based Complement Alternat Med 2008; 5: 281-7.

[12] Lee YL, Cesario T, Wang Y, Shanbrom E, Thrupp L. Antibacterial activity of vegetables and juices. Nutrition 2003; 19: 994-6.

[13] Park YJ, Jeon KH, Kim SH, Bae SJ. The Effect on Antimicrobial and Cytotoxicity of Brassica oleracea L. Fractions. Journal of Life Science 2004; 14: 567-72.

[14] Stratil P, Klejdus B, Kuban V. Determination of total content of phenolic compounds and their antioxidant activity in vegetables-evaluation of spectrophotometric methods. J Agric Food Chem 2006; 54: 607-16.

[15] Murray PR, Baron EJ. Manual of clinical microbiology. 9th ed. ASM Press: Washington, D.C., 2007.

[16] Ulloa M, Hanlin RT. Illustrated dictionary of mycology. American Phytopathological Society (APS) Press: St. Paul, Minn., 2000.

[17] Zgoda JR, Porter JR. A convenient microdilution method for screening natural products against bacteria and fungi. Pharm Biol 2001; 39: 221-5.

[18] Lillis JV, Dawson ES, Chang R, White Jr CR. Disseminated dermal Trichophyton rubrum infection-an expression of dermatophyte dimorphism? J Cutan Pathol 2009.

[19] Richardson MD, Johnson EM. The pocket guide to fungal infection. 2nd ed. Blackwell Pub.: Malden, Oxford, 2006.

[20] Clinical and Laboratory Standard Institute (CLSI). Methods for dilution antimicrobial susceptibility tests for bacteria that grow aerobically; approved standard, CLSI document M07-A8. 8th ed. Wayne, Pennsylvania: Clinical and Laboratory Standards Institute, 2009.

[21] Cheney G. Anti-peptic ulcer dietary factor. J am diet assoc 1950; 26: 668-72.

[22] Hassimotto NM, Genovese MI, Lajolo FM. Antioxidant activity of dietary fruits, vegetables, and commercial frozen fruit pulps. J Agric Food Chem 2005; 53: 2928-35.

[23] Arapitsas P, Sjoberg PJR, Turner C. Characterisation of anthocyanins in red cabbage using high resolution liquid chromatography coupled with photodiode array detection and electrospray ionization-linear ion trap mass spectrometry. Food Chemistry 2008; 109: 219-26.

[24] Lin J, Opoku AR, Geheeb-Keller M, et al. Preliminary screening of some traditional zulu medicinal plants for anti-inflammatory and anti-microbial activities. J Ethnopharmacol 1999; 68: 267-74.

[25] Rios JL, Recio MC. Medicinal plants and antimicrobial activity. J Ethnopharmacol 2005; 100: 80-4.

[26] Bonuel N, Byers P, Gray-Becknell T. Methicillin resistant Staphylococcus aureus (MRSA) prevention through facility-wide culture change. Crit Care Nurs Q 2009; 32: 144-8.

[27] Creel AM, Durham SH, Benner KW, Alten JA, Winkler MK. Severe invasive community-associated methicillin-resistant Staphylococcus aureus infections in previously healthy children. Pediatr Crit Care Med 2009.

[28] Sng LH, Koh TH, Wang GC, Hsu LY, Kapi M, Hiramatsu K. Heterogeneous vancomycin-resistant Staphylococcus aureus (heteroVISA) in Singapore. Int J Antimicrob Agents 2005; 25: 177-9.

[29] Maurer C, Meunier D, Madec JY. Shiga toxin Stx2 production is promoted by enrofloxacin in experimental in vitro-selected mutants of Escherichia coli O157:H7 resistant to fluoroquinolones. Foodborne Pathog Dis 2009; 6: 257-9.

[30] Taccetti G, Campana S, Neri AS, Boni V, Festini F. Antibiotic therapy against Pseudomonas aeruginosa in cystic fibrosis. J Chemother 2008; 20: 166-9.

[31] Paterson DL, Ko WC, Von Gottberg A, et al. International prospective study of Klebsiella pneumoniae bacteremia: implications of extended-spectrum beta-lactamase production in nosocomial Infections. Ann Intern Med 2004; 140: 26-32.

[32] Rayamajhi N, Kang SG, Kang ML, Lee HS, Park KY, Yoo HS. Assessment of antibiotic resistance phenotype and integrons in Salmonella enterica serovar Typhimurium isolated from swine. $\mathrm{J}$ Vet Med Sci 2008; 70: 1133-7.

[33] Walter J, Sobottka I, Rogiers X, Broering D, Fischer L. Invasive aspergillosis caused by Aspergillus terreus in a living donor liver transplant recipient successfully treated by caspofungin. Mycoses 2009. 
[34] Chandrasekar P. Invasive mold infections: recent advances in management approaches. Leuk Lymphoma 2009; 50: 703-15.

[35] Balci DD, Cetin M. Widespread, chronic, and fluconazole-resistant Trichophyton rubrum infection in an immunocompetent patient. Mycoses 2008; 51: 546-8.

[36] Havsteen BH. The biochemistry and medical significance of the flavonoids. Pharmacol Ther 2002; 96: 67-202.

[37] Glinska S, Bartczak M, Oleksiak S, et al. Effects of anthocyaninrich extract from red cabbage leaves on meristematic cells of Allium cepa L. roots treated with heavy metals. Ecotoxicol Environ Saf 2007; 68: 343-50.

[38] Wang SY, Streth AW. Antioxidant capacity in canberry is influenced by cultivar and storage temperature. J Agri Food Chem 2001; 49: 969-74.

[39] Kalt W, Foreney CF, Martin A, Prior RL. Antioxidant capacity, vitamin $\mathrm{C}$, phenolics, and anthocyanins after fresh storage of small fruits. J Agri Food Chem 1999; 47: 4638-44.
[40] Chu YF, Sun J, Wu X, Liu RH. Antioxidant and antiproliferative activities of common vegetables. J Agric Food Chem 2002; 50: 6910-6.

[41] Randhir R, Shetty K. Mung beans processed by solid-state bioconversion improves phenolic content and functionality relevant for diabetes and ulcer management. Innov Food Sci Emerg 2007; 8: 197-204.

[42] Sarma AD, Sharma R. Anthocyanin-DNA copigmentation complex: mutual protection against oxidative damage. Phytochemistry 1999; 52: 1313-8.

[43] Lazze MC, Pizzala R, Savio M, Stivala LA, Prosperi E, Bianchi L. Anthocyanins protect against DNA damage induced by tert-butylhydroperoxide in rat smooth muscle and hepatoma cells. Mutat Res 2003; 535: 103-15.

[44] Kong JM, Chia LS, Goh NK, Chia TF, Brouillard R. Analysis and biological activities of anthocyanins. Phytochemistry 2003; 64: 923-33.

(C) Hafidh et al.; Licensee Bentham Open.

This is an open access article licensed under the terms of the Creative Commons Attribution Non-Commercial License (http://creativecommons.org/licenses/ by-nc/3.0/) which permits unrestricted, non-commercial use, distribution and reproduction in any medium, provided the work is properly cited. 